\title{
Characterization of a novel human protein phosphatase 2C family member, PP2Ck
}

\author{
JIANFENG DAI* , JIYUAN ZHANG ${ }^{*}$, YAQIONG SUN, QIHAN WU, LIYUN SUN, \\ CHAONENG JI, SHAOHUA GU, CONGJING FENG, YI XIE and YUMIN MAO
}

State Key Laboratory of Genetic Engineering, Institute of Genetics, School of Life Sciences, Fudan University, Shanghai 200433, P.R. China

Received November 3, 2005; Accepted February 15, 2006

\begin{abstract}
A novel member of human protein phosphatase 2C gene named $P P 2 C \kappa$ was isolated from a human fetal brain cDNA library. The $2.0 \mathrm{~kb}$ cDNA encodes a 372 amino acid polypeptide with an intact protein phosphatase $2 \mathrm{C}$ (PP2C) catalytic domain. Reverse transcription-PCR (RT-PCR) revealed that the $P P 2 C \kappa$ was widely expressed in normal human tissues. Transient transfection suggested that PP $2 \mathrm{C} \kappa$ was localized in the nucleus in AD293 cells. Recombinant TrxHis-PP2Cк showed phosphatase activity toward $p$-nitrophenyl phosphate ( $p$ NPP), as well as oligopeptides containing phospho-threonine residues. Furthermore, the overexpression of $\mathrm{PP} 2 \mathrm{C} \kappa$ distinctly activated the heat shock transcription factor pathway in eukaryotic cells.
\end{abstract}

\section{Introduction}

Protein phosphorylation/dephosphorylation is recognized as a major regulatory mechanism of cellular functions such as cell signal transduction and cell cycle controlling. Protein phosphatase $2 \mathrm{C}$ (PP2C) is one of four major protein serine/ threonine phosphatases (PP1, PP2A, PP2B and PP2C) in eukaryotes $(1,2)$. It is distinguished from other groups of phosphatases by its structural distinction, absolute requirement for divalent cation $\left(\mathrm{Mg}^{2+}\right.$ or $\left.\mathrm{Mn}^{2+}\right)$ and insensitivity to the okadaic acid $(1,2)$. To date, at least 9 different PP2C genes have been identified in mammalian cells, such as $P P 2 C \alpha, 2 C \beta, 2 C \gamma$, $2 C \delta$ (Wipl), $2 C \varepsilon, 2 C \xi, 2 C \eta$, ILKAP-PP $2 C, \mathrm{Ca}^{2+} /$ calmodulindependent protein kinase phosphatase (3-12) and so on. There are even more $\mathrm{PP} 2 \mathrm{C}$ isoforms in plants and other organisms reported in the past few years (12), and they compose a large gene family.

Correspondence to: Dr Yi Xie or Dr Yumin Mao, State Key Laboratory of Genetic Engineering, Institute of Genetics, School of Life Sciences, Fudan University, Shanghai 200433, P.R. China E-mail: ymmao@fudan.edu.cn

\section{${ }^{*}$ Contributed equally}

Key words: PР2Cк, phosphotase activity, HSF signal pathway, subcellular localization
Each protein phosphatase $2 \mathrm{C}$ isoform has an approximate 250 amino acid PP2C catalytic domain, which includes six typical motifs with highly conserved amino acid residues for metal ion $\left(\mathrm{Mg}^{2+}\right.$ or $\left.\mathrm{Mn}^{2+}\right)$ binding (1). In addition to catalytic domain, PP2C isoforms usually have unique $\mathrm{C}$-terminal or $\mathrm{N}$-terminal regions which may be involved in determination of substrate specificity.

Recent research data demonstrated that some major PP2Cs are involved in the regulation of mitogen-activated protein kinase (MAPK) cascades which deliver signals in response to extracellular stimulus (13-17). MAPK pathways, especially stress-activated protein kinase (SAPK) pathways, are negatively regulated by multiple $\mathrm{PP} 2 \mathrm{C}$ isoforms at different levels (18). Evidence also exists indicating that PP2C isoforms play important roles in regulation of cell cycle (19$21)$, apoptosis (22-24), and the nerve system-related signal pathway (25-27).

In recent work, we have isolated a novel human PP2C isoform gene through the large-scale sequencing analysis of human fetal brain cDNA library. Its predicted protein has a typical PP2C catalytic domain and shows $\mathrm{Mn}^{2+} / \mathrm{Mg}^{2+}-$ dependent phosphatase activity. We termed it human protein

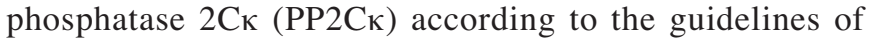
Human Genome Organization (HUGO) Nomenclature Committee. Herein we report the initial characterization of this novel gene and its potential role in eukaryotic cell signal transduction.

\section{Materials and methods}

Cloning of PP2C $\mathrm{CDNA}$. A human cDNA, which encodes a novel human protein phosphatase $2 \mathrm{C}$, was cloned from the human fetal library during large-scale cDNA sequencing. The cDNA library was constructed in a modified pBluescript II SK (+) vector with human fetal brain mRNA purchased from Clontech. A $0.5 \mathrm{~kb}$ DNA fragment containing 2 SfiI A (5'GGCCATTATGGCC-3') and SfiI B (5'-GGCCGCCTCGG CC-3') recognition sites were introduced into the EcoRI and NotI sites of pBluescript II SK (+) (Stratagene); doublestranded cDNAs were synthesized using SMART ${ }^{\mathrm{TM}}$ cDNA Library Construction kit (Clontech) following the manufacturer's instructions. The cDNA inserts were sequenced on an ABI PRISM ${ }^{\mathrm{TM}} 377$ DNA sequencer (Perkin-Elmer) using the BigDye Terminator Cycle Sequencing Kit and BigDye Primer Cycle Sequencing Kit (Perkin-Elmer) with -21M13 
primer, M13Rev primer and synthetic internal walkingprimers designed according to the obtained cDNA sequence fragments. Subsequent editing and assembly of all the sequences from one clone was performed using Acembly (Sanger's Center).

Bioinformatic analysis. DNA and protein sequence comparisons were carried out using BLAST2.0 at NCBI (http:// www.ncbi.nlm.nih.gov/blast). ProfileScan was done by ANTHEPROT V5.0 (http://pbil.ibcp.fr/ANTHEPROT) (author: G. Deleage). Sequence alignment was performed by AlignX [http://www.informaxinc.com/vectorNTI (v6.0)] and GENEDOC (http://www.cris.com/ Ketchup/genedoc.shtml).

Expression pattern of PP2C . Two human adult multiple tissue cDNA (MTC) panels and one human fetal MTC panel (Clontech) were used as PCR templates according to the manufacturer's protocol. Thirty-two PCR cycles for human $P P 2 C \kappa$ and 30 cycles for $G A P D H$ (as control) were performed using Taqplus DNA polymerase (Sangon) according to the following program: $30 \mathrm{sec}$ at $94^{\circ} \mathrm{C}, 30 \mathrm{sec}$ at $65^{\circ} \mathrm{C}$ and $1.0 \mathrm{~min}$ at $72^{\circ} \mathrm{C}$. The PCR products of $P P 2 C \kappa$ and $G A P D H$ were then electrophoresed on a $2 \%$ agarose gel. PCR primers are indicated from 5' to $3^{\prime}$ as follows: human $P P 2 C \kappa$ sense, ATGTCAACAGCTGCCTTAATTACTT; human $P P 2 C \kappa$ antisense, TCAGGCCCATCGTCCACTGGAG; GAPDH sense, TGAAGGTCGGAGTCAACGGATTTGGT; GAPDH antisense, CATGTGGGCCATGAGGTCCACCAC. The sense primer and the antisense primer of $P P 2 C \kappa$ span $1118 \mathrm{bp}$ in the cDNA from 214 to $1332 \mathrm{bp}$.

Construction of expression plasmids. Expression plasmids were constructed by standard procedures. For bacterial expression of proteins, the open reading frame of $P P 2 C \kappa$ was subcloned into the pET32a vector (Novagen) to generate Trx-His-tag fusion protein. Plasmids that express $\mathrm{PP} 2 \mathrm{C} \kappa$ in mammalian

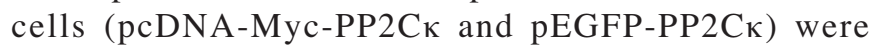
constructed using PP2CK cDNA together with the pcDNA4/ Myc-His-C (Invitrogen) and pEGFP-C1 (Clontech) vectors, respectively.

Expression in E. coli and purification of PP2C $\kappa$. Transformants of $E$. coli BL21 with the pET32a-PP2Cк plasmid were grown at $37^{\circ} \mathrm{C}$ in $500 \mathrm{ml} \mathrm{LB}$ medium with $100 \mu \mathrm{g} / \mathrm{ml}$ ampicillin. When the culture had grown to an $\mathrm{OD}_{600}$ of 0.6 , isopropyl b-Dthiogalactopyranoside (IPTG) was added to a final concentration of $1 \mathrm{mM}$. After inducing the expression of the Trx-His-PP2Ck protein for $4 \mathrm{~h}$ at $28^{\circ} \mathrm{C}$, cells were harvested, washed and lysed in $50 \mathrm{ml} \mathrm{BugBuster}$ protein extraction reagent (Novagen). Protein was purified from the soluble fraction with Ni-NTA agrose column (Qiagen) according to the manufacturer's protocol. The protein concentration was determined by the method of Bradford using BSA as a standard. The integrity of the fusion protein was checked by SDS-PAGE.

Phosphatase assay. The standard reaction which contained $1 \mu \mathrm{g}$ of protein, $50 \mathrm{mM}$ Tris- $\mathrm{HCl}(\mathrm{pH} 6.0), 10 \mathrm{mM} p$-nitrophenyl phosphate $(p \mathrm{NPP})$ and $5 \mathrm{mM}$ divalent cation $\left(\mathrm{Mg}^{2+}\right.$ or $\mathrm{Mn}^{2+}$ ) in a total of $1 \mathrm{ml}$ was performed at $37^{\circ} \mathrm{C}$ for $30 \mathrm{~min}$ and then stopped by $0.1 \mathrm{M} \mathrm{NaOH}$. The increase in the amount of p-nitrophenol was monitored by measuring the absorbance at $420 \mathrm{~nm}$ on an Ultraspec 4000 (Pharmacia) spectrophotometer. The serine/threonine phosphatase assay system (Promega) was used to detect the serine/threonine phophatase activity of PP2Cк. The reactions contained $20 \mu 15 \mathrm{X}$ reaction buffer (provided by the assay system), $10 \mu 1$ phosphopeptide (provided by the assay system) and different concentrations of PP2CK in a total of $100 \mu 1$. The reaction was stopped by adding $100 \mu 1$ of molybdate dye/additive mixture and the standard curve was made according to the manufacturer's protocol. The released phosphate was monitored by measuring the absorbance at $600 \mathrm{~nm}$ on Model 450 Microplate Reader (Bio-Rad). The Thr phosphopeptide sequence was RRA (pT)VA.

Cell culture, transfection, and pathway profiling assay. We used Mercury Pathway Profiling System (Clontech) to investigate the potential roles of $\mathrm{PP} 2 \mathrm{C} \kappa$ in the signal pathways, and firefly luciferase as the reporter gene. AD293 cells and NIH3T3 cells were cultured in Dulbecco's modified Eagle's medium containing $10 \%$ fetal bovine serum. The cells were seeded on a 96-well plate at $1 \times 10^{4} /$ well. After 24

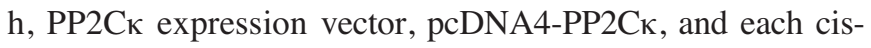
acting luciferase reporter vector of the Mercury Pathway Profiling System (Clontech) were co-transfected into cells by the Lipofectamine 2000 (Invitrogen) according to the manufacturer's protocol. After $48 \mathrm{~h}$, the transfected cells were lysed and the activity of luciferase reporter gene was measured by dual-luciferase reporter assay system (Promega). We also designed the transfection assay in a plasmid dosedependent manner after we got our primary results.

Subcellular localization of PP2Cк. AD293 cells were transiently transfected with pEGFP-PP2CK and pEGFP-C1 (as control) using Lipofectamine 2000 (Invitrogen). Fortyeight hours after transfection, cells were fixed with $4 \%$ paraformaldehyde for $20 \mathrm{~min}$ at room temperature (RT), washed with PBS (pH 7.4), and then nuclei were stained with DAPI (4',6'-diamidino-2-phenylindole). Fluorescence was viewed with a Leica fluorescence microscope. EGFP served as the control.

\section{Results}

Identification and cloning of human PP2C $\mathrm{cDNA}$. The GenBank non-redundant and EST databases were searched with individual sequences from our collection of full-length assembled cDNAs using the NCBI BLAST server in order to identify sequences of interest. A 2034 bp cDNA was isolated which contains an open reading-frame from nucleotide 214 to 1332, encoding a 372 amino acid protein with a calculated molecular mass of $\sim 46 \mathrm{kDa}$. (GenBank accession number for this cDNA is AY157615). The deduced protein has an intact protein phosphatase $2 \mathrm{C}$ catalytic domain from amino acid residue 95 to 344 which shows high similarity with the human $\mathrm{PP} 2 \mathrm{C} \varepsilon, \mathrm{hPP} 2 \mathrm{C} \alpha 1$, and hPP2Cß1 catalytic domains (Figs. 1 and 2). All the typical motifs (I-VI) and conserved amnio acid residues for metal ions binding were also found in the predicted PP2C catalytic domain (Figs. 1 and 2). We termed this gene human $P P 2 C \kappa$ (protein phosphatase $2 \mathrm{C \kappa}$ ). The protein phosphatase $2 \mathrm{C} \kappa$ gene is mapped to human chromosome $4 \mathrm{q} 22$ by BLAST search 
34 actgcttgcttcggagatccgagacgacggagaaggcactcttatttaccgaccaagaaagctcctcccccgtcctcogttagctaatta 124 aaacatttttcagggacgtagccatccagagacattccattattgttccattgacctttccctcatcactgagtcctttggagctgagt $t$ 214 atgtcaacagctgccttaattactttggtcagaagtggtgggaaccaggtgagaaggagagtgctgctaagctccegcctgctgcaggac I M S T A A L I T L V R S G G N O V R R R V L L S S R L L O D 304 gacaggcgggtgacacccacgtgccacagctccacttcagagcctaggtgttctcggtttgacccagatggtagtgggagtccagctacc

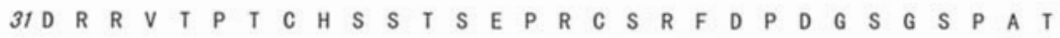
394 tgggacaattttgggatctgggataaccgcattgatgagccaattctgctgccacccagcattaagtatggcaagccaat tcccaaaatc 61 W $D$ D $N$ N $F$ G I 484 agcttggaaaatgtggggtgcgcctcacagattggcaaacggaagagaatgaagatcggtttgacttcgctcagctgacagatgaggtc gI S L E N V G C A S Q I G K K R K E N E D R F D F A Q Q L T D E E V [1]

574 ctgtactttgcagtgtatgatggacacggtggacctgcagcagctgatttctgtcatacccacatggagaaatgtattatggatttgctt $121 \mathrm{~L} Y \mathrm{Y} F \mathrm{~A} V \mathrm{Y}$ D G H G G P A A A D F C H T H M E K C I M D L L [II]

664 cctaaggagaagaacttggaaactctgttgaccttggcttttctagaaatagataaagccttttcgagtcatgccegcctgtctgctgat 151 P K E K N L E T L L T L A F L E I D K A F S S HA R L S A D 754 gcaactcttctgacctctgggactactgcaacagtagccctattgcgagatggtattgaactggttgtagccagtgttggggacagccgg 181 A T L L T S G T T A T V A L L R D G I E L V V A S V V G D S R

[III]

844 gctattttgtgtagaaaaggaaacccatgaagctgaccattgaccatactccagaaagaaagatgaaaagaaaggatcaagaaatgt $211 A$ I L C R K G K P M K L T I D H T P E R K D E K E R I K K C 934 ggtggttttgtagettggaatagtttggggcagcctcacgtaaatggcaggcttgcaatgacaagaagtattggagatttggaccttaag $241 G$ G F V A W N S L G Q P H V N G R L A M I R S I G D L D L K

1024 accagtggtgtcatagcagaacctgaactaagaggattaagttacatcatgctgatgacagcttcctggtcctcaccacagatggaatt 27IT S G V I A E P E T K R I K L H H A D D S F L V L L T T D

1114 aacttcatggtgaatagtcaagagatttgtgactttgtcaatcagtgccatgatcccaacgaagcagcccatgcggtgactgaacaggca 301 N F M V N S O E I C D F V N O C H D P N E A A H A V T E O A 1204 atacagtacggtactgaggataacagtactgcagtagtagtgccttttggtgcctggggaaaatataagaactctgaaatcaacttctca 331 I O Y G T E D N S T A V V V P F G A W G K Y K N S E I N F S

1294 ttcagcagaagctttgcctccagt ggacgatgggcctgat taccagctgggacttagagtttctgtgcaacagtttttcactgagcatgt 361 F S R S F A S S G R W A *

1384 caagaaactgataagatcaaaaggtctcctaactcactagatcagcgcacaagtcagtgtaaaccacttagatagtagttttttcataa 1474 atgctcatcatatttatgttccgctgtacatgttcagtataaatatatgtgtagtgaagctactgtgagtctttaaatggaaagagcaaa 1564 tgagaagtggtttggatacacttgatgagagatgagagtgtcacattaataatttttaagactcttaggcagctatgggtttcttttgat 1654 catttttgttctttattcatttgaacacgtttttgaagttcttcaaactagtcagtttgaattttgacagctattcaatatgtgatctc 1744 caagtttaaaaaat $t t t t t c c a g a c t t c c c t a a t c c t a a a t g c g a g t t t t t a t t t t$ taataactgtaccaaggaataagtatgaaaa 1834 cagttctctgttaccatattttgtattctggaccacttactggtgaaagcaaccatgcaaaagaattaatttggccaggcacagtggct 1924catgcctgtaatcccagcactttgggaggccaaggtgggtagatcatctgaggtcaggaat tcaagaccagcctggccaacatggtgaaa 2014 ccotgtctctagtaaaatcc

Figure 1. The cDNA and deduced amino acid sequences of human $P P 2 C \kappa$ gene. The nucleotides and amino acids are numbered on the left (italics indicates amino acids). The protein phosphatase $2 \mathrm{C}$ catalyzed domain (from residue 95 to 344 ) is shaded. The six PP2C motifs are underlined and the conserved amino acid residues are indicated in bold text.

against human genome database. The cDNA spans about 23 $\mathrm{kb}$ on the chromosome and consists of 7 exons.

Expression pattern of the PP2CK gene. The tissue distribution of $P P 2 C \kappa$ mRNA was determined by RT-PCR using multiple tissue cDNA (MTC) panels (Clontech) as PCR templates.
$P P 2 C \kappa$ mRNA was detected in all the human tissues we used, which indicates that $P P 2 C \kappa$ is widely expressed and relatively abundant. The expression levels in adult heart, brain, kidney, pancreas and ovary are relatively high. In eight fetal tissues, $P P 2 C \kappa$ showed high expression in heart and thymus (Fig. 3). 


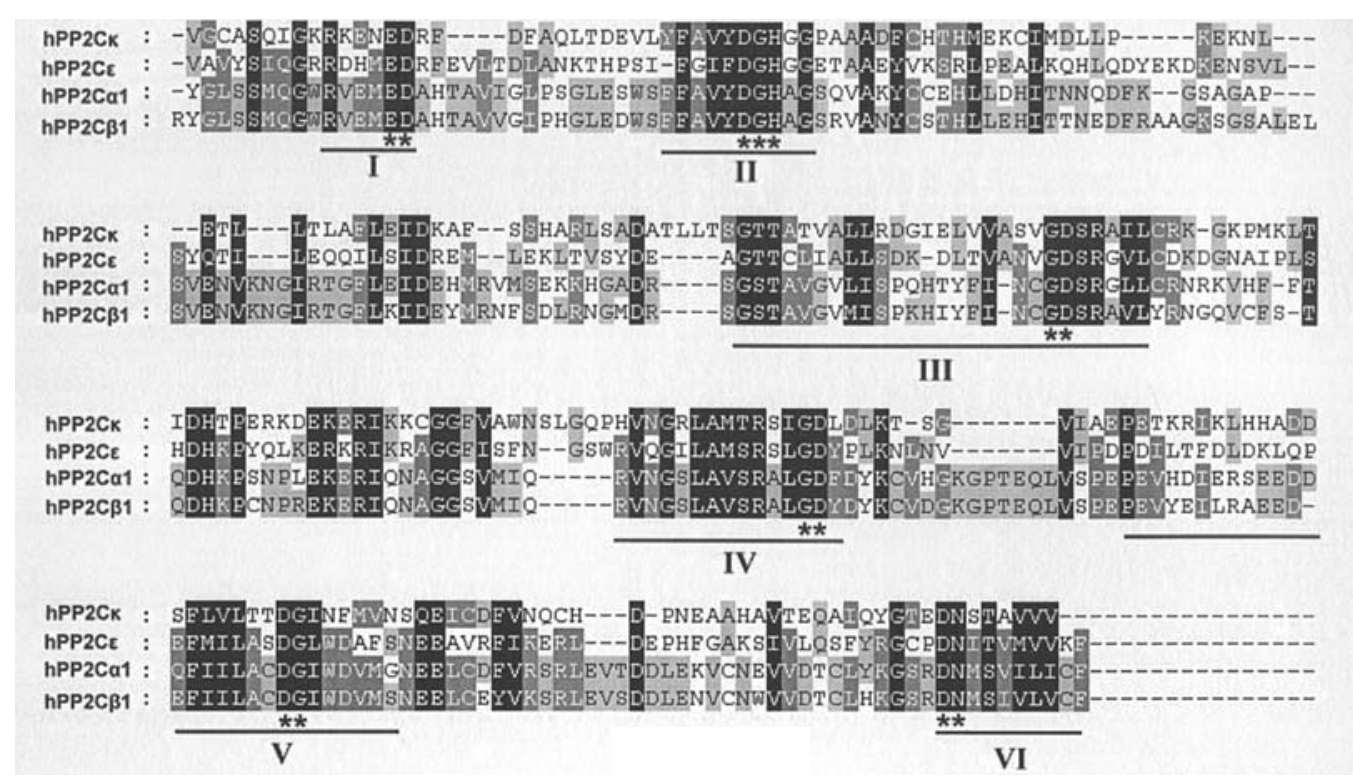

Figure 2. Sequence comparison of PP2Cк phosphatase catalytic domain with those of hPP2C $\varepsilon$ (AAR00269), hPP2C $\alpha 1$ (P35813), and hPP2CB1 (CAA06704). Identical amino acids and homologous amino acids are indicated by solid boxes and shaded boxes, respectively. Typical motifs and conserved residues are indicated.

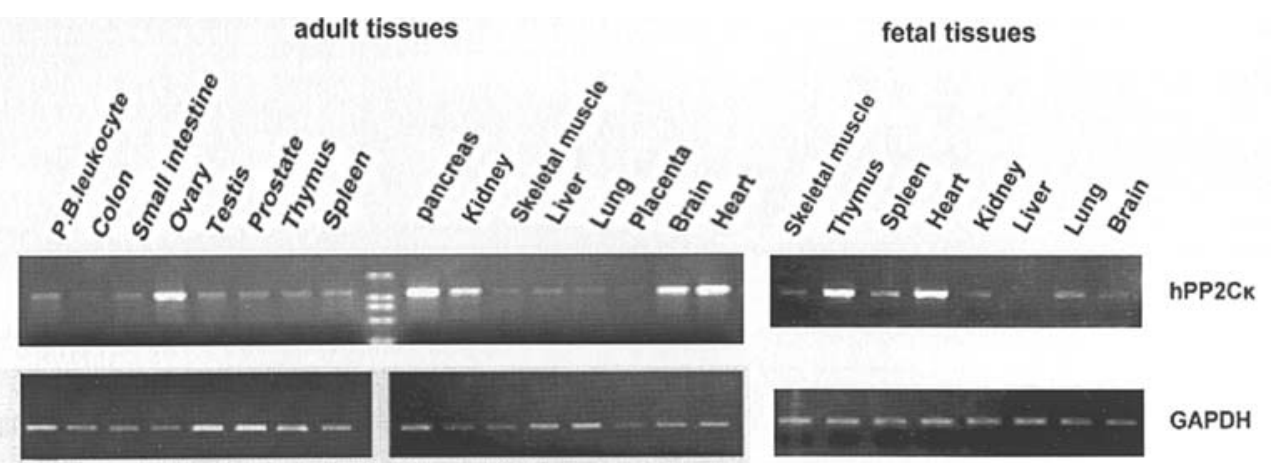

Figure 3. Tissue distribution of $P P 2 C \kappa$ mRNA. Reverse transcription-PCR analysis of human cDNA for $P P 2 C \kappa$ and $G A P D H$ (as a control). Prenormalized cDNAs from sixteen human adult tissues and eight human fetal tissues were employed as templates in PCR reactions.

Expression in E. coli and purification of PP2CK. Following induction with IPTG, the Trx-His recombinant $\mathrm{PP} 2 \mathrm{C} \kappa$ yielded a major band of apparent molecular mass of $66 \mathrm{kDa}$ on an SDS-PAGE gel corresponding to about $15-20 \%$ of the total applied protein (Fig. 4A). Purification was performed by Ni-NTA agrose column (Qiagen). The purified protein was deionized and eluted.

In vitro enzymatic properties of $P P 2 C \kappa$. The phosphatase activity of Trx-His-PP2CK on pNPP was first examined. The Trx-His-PP2C $\mathrm{K}$ had divalent cation $\left(\mathrm{Mg}^{2+}\right.$ or $\left.\mathrm{Mn}^{2+}\right)$ dependent phosphatase activity which was relatively high in the presence of $\mathrm{Mn}^{2+}$ (Fig. 4B). The phophatase activity was not affected by $1 \mu \mathrm{M}$ okadaic acid (OA) (data not shown). We investigated the substrate specificity of Trx-His-PP2Ck using the serine/threonine phosphatase assay system (Promega). In this assay, the enzyme activity was estimated by measuring the amount of the phosphate released. Trx-HisPP2Cא showed phosphatase activity toward pThr (Fig. 4C). These data showed that $\mathrm{PP} 2 \mathrm{C} \kappa$ is a protein phosphatase with serine/threonine phosphatase activity and it is a novel isoform of the PP2C family.
Pathway profiling. To find the potential roles of PР2CK in the cell signal transduction pathway, we overexpressed $\mathrm{PP} 2 \mathrm{C} \kappa$ in eukaryotic cells and investigated its roles by Mercury Pathway Profiling System. We used 6 cis-acting luciferase reporter vectors [cAMP response element (CRE), serum response element (SRE), nuclear factor of $\kappa B$ cells $(\mathrm{NF}-\mathrm{kB})$, heat shock response element (HSE), activator protein 1 (AP1), and glucocorticoid response element (GRE)] in AD293 cells and 4 cis-acting luciferase reporter vectors [E-box DNA binding element (Myc), p53 response element (P53), E2F DNA binding element (E2F), and $\mathrm{Rb}$ response element $(\mathrm{Rb})$ ] in NTH3T3 cells. Considering that the AD293 cell line is a transformed cell line, we assayed the above 4 types of cell-cycle related pathways in NIH 3T3 cells. In all the tests, the TAL promoter weak reporter was used as a control. The results indicate that $\mathrm{PP} 2 \mathrm{C} \kappa$ distinctly activated the heat shock response element (HSE) pathway (also named heat shock factor pathway) about 7-fold, but had no effect on the other 9 pathways we used (Fig. 5A and B). The dose-depended assays in both AD293 and NIH3T3 cells verified the activation of $\mathrm{PP} 2 \mathrm{C} \kappa$ to the heat shock factor pathway (Fig. 5C and D). 
A

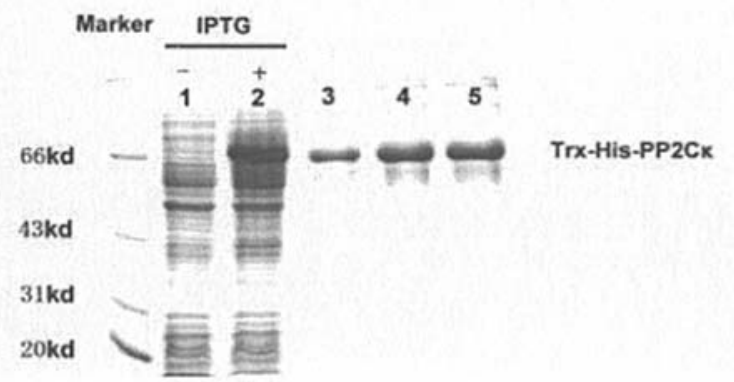

Figure 4. (A) SDS-PAGE gel analysis of protein samples. Lane 1, total cell protein sample before induction by IPTG; lane 2, total cell protein sample after induced by $1 \mathrm{mM}$ IPTG for $4 \mathrm{~h}$; lanes 3-5, recombinant protein sample after purification by Ni-NTA agrose column. (B) Basic enzymatic properties of PP2CK: the phosphatase activity of Trx-His-PP2 $\mathrm{C} \kappa$ and Trx-His (as control) using $10 \mathrm{mM}$ pNPP as substrate; (C) Ser/Thr phosphatase activity of PP2Cк. 0.1 mM Thr phosphopeptide [RRA (pT)VA] was used as substrate. Indicated amounts of $\mathrm{PP} 2 \mathrm{C} \kappa$ were assayed.
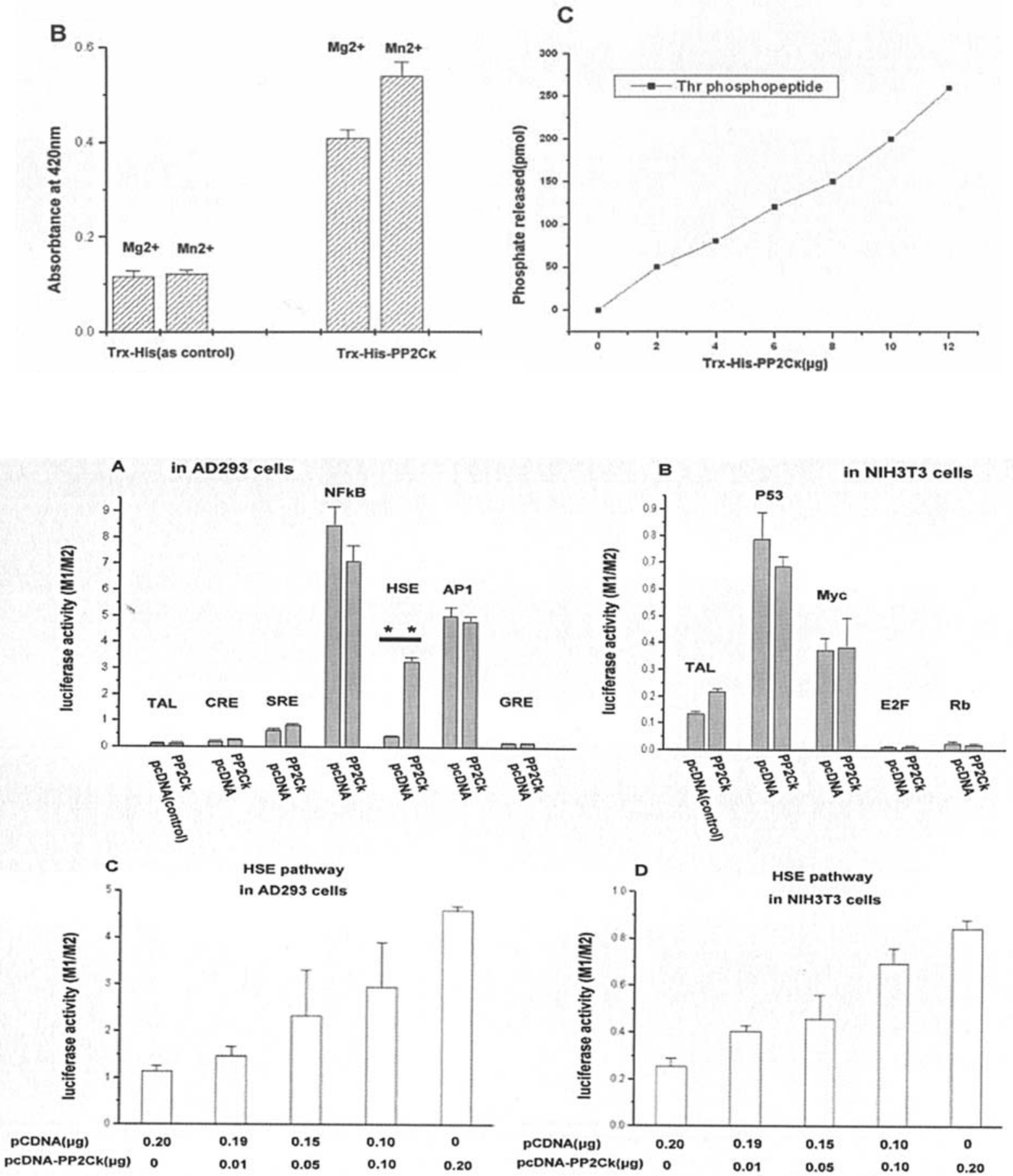

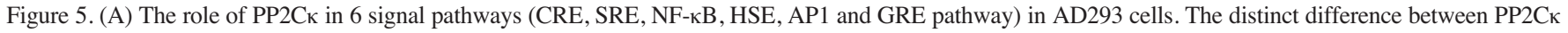
and pcDNA control are indicated by asterisks. (B) The role of PP2Ck in 4 cell-cycle related signal pathways (P53, Myc, E2F and Rb pathway) in NIH3T3 cells. (C) Activation of HSE pathway by PP2CK in a dose-dependent manner in AD293 cells. (D) Activation of HSE pathway by PP2CK in a dose-dependent manner in NIH3T3 cells. 


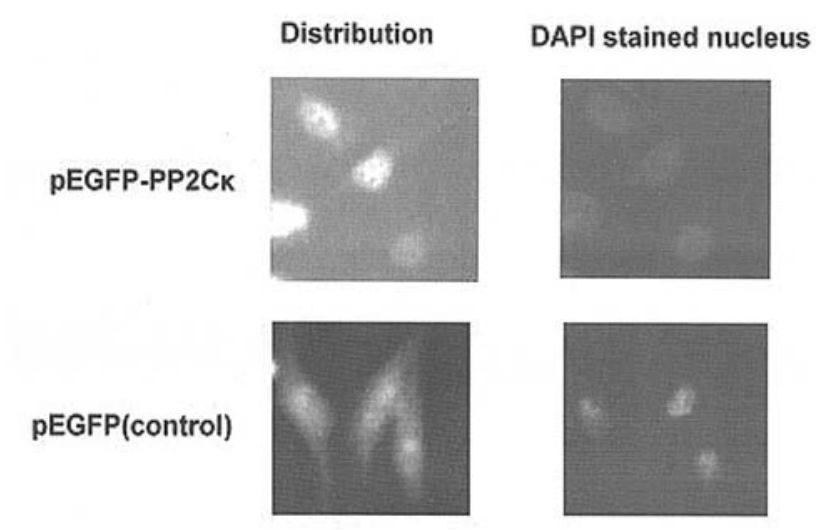

Figure 6. Subcellular localization of PP2Cк. AD293 cells transfected with pEGFP-PP2Cк were fixed and stained with 4',6'-diamidino-2-phenylindole dihydrochloride (DAPI). The pEGFP-C1 vector was used as a control.

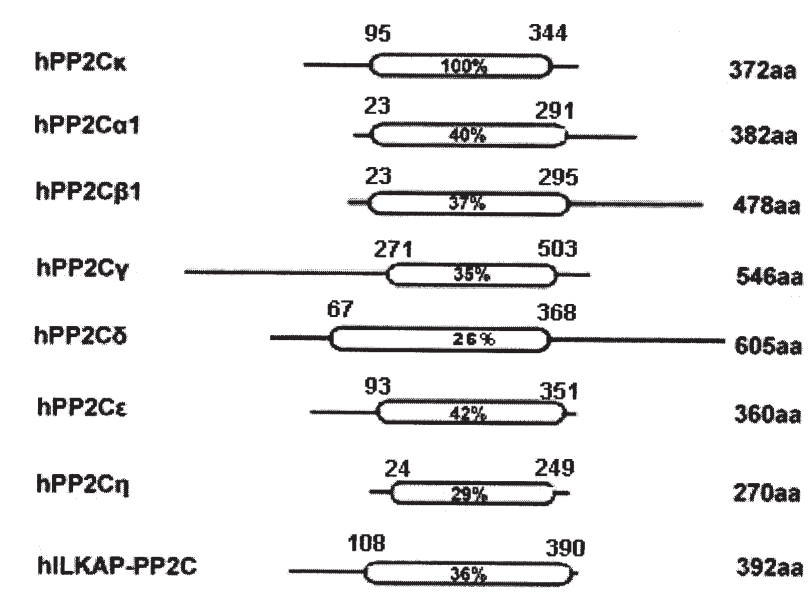

Figure 7. Domain structure of the members of the human PP2C family. The catalytic domains of human PP2Cк, PP2C $\alpha 1$ (P35813), PP2CB1 (CAA06704), PP2C $\gamma($ CAA74245), PP2C $\delta$ (O15297), PP2C $\varepsilon$ (AAR00269), PP2C (Q96MI6), and ILKAP-PP2C (NP_110395) are depicted with boxes. The residue positions of each catalytic domain are indicated on both ends of the domains. The homology between PP2Ck with other PP2Cs is shown.

Subcellular localization of PР2Ск. Subcellular localization

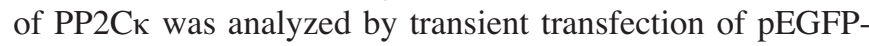
PP2CK recombinant plasmid to AD293 cells. Green fluorescence revealed that $\mathrm{PP} 2 \mathrm{C} \kappa$ was expressed in the cell nucleus [nucleus was stained with DAPI (4',6'-diamidino-2phenylindole dihydrochloride)] (Fig. 6).

\section{Discussion}

The distinct protein structure features and increasing gene family background of protein phosphatase $2 \mathrm{C}$ help us to identify new members of PP2C isoforms in mammals. We report on a new isoform of human PP2C family named $P P 2 C \kappa$. The $2.0 \mathrm{~kb}$ cDNA encodes a 372 amino acid protein containing an intact PP2C catalytic domain from residue 95 to 344 and a unique $\mathrm{N}$-terminal region. Six typical motifs and several key amino acid residues (shown in Figs. 1 and 2) are conserved in all known members of PP2C family. The crystal structure reveals that these motifs compose a central $B$ - sandwich binding two manganese ions surrounded by $\alpha$ helices. $\mathrm{Mn}^{2+}$-bound water molecules at the binuclear metal center coordinate the phosphate group of substrates and provide a nucleophile and general acid in the dephosphorylation reaction $(1,28)$. Glu-37(G), Asp-38(D), Asp60(D), Asp-239(D) and Asp-282(D) are essential for the binding of metal ions and $\mathrm{H}_{2} \mathrm{O}$ molecules in the catalytic site of PP2C isoforms (residue number is from PP2C $\alpha$ ) $(1,28,29)$. All the key motifs and conserved residues were found in the PP2C domain of PP2CK, which suggested that it was a new functional PP2C isoform (Figs. 1 and 2). The primary phosphatase assay verified its basic serine/threonine phophatase activity (Fig. 4).

Apart from the 250-residue PP2C catalytic domains, most mammalian $\mathrm{PP} 2 \mathrm{C}$ isoforms have their unique $\mathrm{C}$-terminal regions or $\mathrm{N}$-terminal regions (Fig. 7). Deletion analysis indicated that these polypeptide regions did not affect the catalytic activity and they may play roles in determination of substrate specificity. The low sequence similarity among PP2C members suggests that PP2C gene family is formed by a convergent evolution (Fig. 7).

$P P 2 C \kappa$ is ubiquitously expressed in all the normal tissues we studied and its expression levels display notable differences in various tissues. Previous studies indicate that PP2C isoforms have different expression patterns in mammals. For example, $P P 2 C \alpha, \beta$, and $\delta$ are ubiquitously expressed, but $P P 2 C \varepsilon, \zeta$ show tissues specific expression pattern $(3,4,6,8,9) . P P 2 C \alpha$ and $P P 2 C \beta$ even have 2 and 5 isoforms, respectively (17). The different distributions of PP2Cs may determine their distinct substrate specificities and individual functions in vivo.

With the help of the Mercury Pathway Profiling System, we found that $\mathrm{PP} 2 \mathrm{C} \kappa$ could stimulate the activities of the heat shock factor pathway. It has been reported that phosphorylation may provide sophisticated regulation of transcription factors, including heat shock factor 1 (HSF1) (30). At least five phosphorylation sites, Ser230, Ser303, Ser307, Ser206, Ser363, have been reported in heat shock factor 1 , and all these sites are phosphorylated constitutively and are inducible. The phosphorylation can positively or negatively regulate the transcriptional activity of HSF1 (3035). The heat shock factor is inhibited by at least five kinases such as ERK, JNK and GSK3ß (30), but up to now, no phosphatases have been isolated in the regulation of the heat shock factor pathway. We presume that PP2Cא may regulate the activity of the heat shock factor in two ways: 1) the $\mathrm{PP} 2 \mathrm{C} \kappa$ directly interacts with the heat shock factor and dephosphoralyted the phospho-serine residues, 2) PP2CK influences the heat shock factor pathway indirectly by inactivating the kinases, such as JNK, ERK and GSK3ß. Some other members of PP2C family can influence the JNK and p38 pathways. Further research will focus on the detailed mechanism of the regulatory function of PP2Cк. For example, demonstrating the possible interaction between PP2CK and the aforementioned kinases or HSF1 in vivo.

We investigated the subcellular localization of PР2Cк by transiently transfected GFP recombinant $\mathrm{PP} 2 \mathrm{C \kappa}$ into the AD293 cell line. PP2Cא was observed only in the nucleus in the transfected cells. It is consistent with our results that $\mathrm{PP} 2 \mathrm{C} \kappa$ activates the heat shock factor in cell nucleus. 
In conclusion, a novel human PP2C isoform: PP2Cא was isolated. Its tissue distribution and initial phosphatase activity were determined. PP2Cא may function as an active regulator in the heat shock factor pathway. Further research is required to confirm our speculation and to reveal the functional model.

\section{Acknowledgments}

This work was supported by the National Science Foundation of China (30370780) and the Major Program of the National Science Foundation of China (10490190). The nucleotide sequence reported in this study has been submitted to GenBank under accession number AY157615.

\section{References}

1. Barford D, Das AK and Egloff MP: The structure and mechanism of protein phosphatases: insights into catalysis and regulation. Annu Rev Biophys Biomol Struct 27: 133-164, 1998.

2. Barford D: Molecular mechanisms of the protein serine/threonine phosphatases. Trends Biochem Sci 21: 407-412, 1996

3. Tamura S, Lynch KR, Larner J, Fox J, Yasui A, Kikuchi K, Suzuki Y and Tsuiki S: Molecular cloning of rat type 2C (IA) protein phosphatase mRNA. Proc Natl Acad Sci USA 86: 1796-1800, 1989.

4. Wenk J, Trompeter HI, Pettrich KG, Cohen PTW, Campbell DG and Mieskes G: Molecular cloning and primary structure of a protein phosphatase 2C isoform. FEBS Lett 297: 135-138, 1992.

5. Travis SM and Welsh MJ: PP2C $\gamma$ : a human protein phosphatase with a unique acidic domain. FEBS Lett 412: 415-419, 1997.

6. Tong Y, Quirion R and Shen SH: Cloning and characterization of a novel mammalian PP2C isozyme. J Biol Chem 273: 35282-35290, 1998.

7. Leung-Hagesteijn C, Mahendra A, Naruszewicz I and Hannigan GE: Modulation of integrin signal transduction by ILKAP, a protein phosphatase $2 \mathrm{C}$ associating with the integrinlinked kinase, ILK1. EMBO J 20: 2160-2170, 2001.

8. Li MG, Katsura K, Nomiyama H, Komaki K, Ninomiya-Tsuji J, Matsumoto K, Kobayashi T and Tamura S: Regulation of the interleukin-1-induced signaling pathways by a novel member of protein phosphatase 2C family (PP2C ع). J Biol Chem 278: 12013-12021, 2003.

9. Kashiwaba M, Katsura K, Ohnishi M, Sasaki M, Tanaka H, Nishimune $\mathrm{Y}$, Kobayashi $\mathrm{T}$ and Tamura $\mathrm{S}$ : A novel protein phosphatase 2C family member (PP2C ) is able to associate with ubiquitin conjugating enzyme 9. FEBS Lett 538: 197-202, 2003.

10. Fiscella M, Zhang H, Fan S, Sakaguchi K, Shen S, Mercer WE, Vande Woude GF, O'Connor PM and Appella E: Wip1, a novel human protein phosphatase that is induced in response to ionizing radiation in a p53-dependent manner. Proc Natl Acad Sci USA 94: 6048-6053, 1997

11. Kitani T, Ishida A, Okuno S, Takeuchi M, Kameshita I and Fujisawa H: Molecular cloning of $\mathrm{Ca}^{2+} /$ calmodulin-dependent protein kinase phosphatase. J Biochem 125: 1022-1028, 1999.

12. Komaki K, Katsura K, Ohnishi M, Li MG, Sasaki M, Watanabe M, Kobayashi T and Tamura S: Molecular cloning of PP2Ceta, a novel member of the protein phosphatase $2 \mathrm{C}$ family. Biochim Biophys Acta 1630: 130-137, 2003.

13. Schweighofer A, Hirt H and Meskiene I: Plant PP2C phosphatases: emerging functions in stress signaling. Trends Plant Sci 9: 236-243, 2004

14. Meskiene I, Baudouin E, Schweighofer A, Liwosz A, Jonak C, Rodriguez PL, Jelinek $\mathrm{H}$ and Hirt H: Stress-induced protein phosphatase $2 \mathrm{C}$ is a negative regulator of a mitogen-activated protein kinase. J Biol Chem 278: 18945-18952, 2003.

15. Nguyen AN and Shiozaki K: Heat-shock-induced activation of stress MAP kinase is regulated by threonine- and tyrosinespecific phosphatases. Genes Dev 13: 1653-1663, 1999.
16. Hanada M, Kobayashi T, Ohnishi M, Ikeda S, Wang H, Katsura K, Yanagawa Y, Hiraga A, Kanamaru R and Tamura S: Selective suppression of stress-activated protein kinase pathway by protein phosphatase 2C in mammalian cells. FEBS Lett 437: 172-176, 1998.

17. Hanada M, Ninomiya-Tsuji J, Komaki K, Ohnishi M, Katsura K, Kanamaru R, Matsumoto K and Tamura S: Regulation of the TAK1 signaling pathway by protein phosphatase 2C. J Biol Chem 276: 5753-5759, 2001.

18. Tamura S, Hanada M, Ohnishi M, Katsura K, Matsumoto K and Kobayashi T: Regulation of stress-activated protein kinase signaling pathways by protein phosphatases. Eur J Biochem 269: 1060-1066, 2002.

19. Cheng A, Ross KE, Kaldis P and Solomon MJ: Dephosphorylation of cyclin-dependent kinases by type $2 \mathrm{C}$ protein phosphatases. Genes Dev 13: 2946-2957, 1999

20. Cheng A, Kaldis P and Solomon MJ: Dephosphorylation of human cyclin-dependent kinases by protein phosphatase type 2C alpha and beta 2 isoforms. J Biol Chem 275: 34744-34749, 2000.

21. Ofek P, Ben-Meir D, Kariv-Inbal Z, Oren M and Lavi S: Cell cycle regulation and $\mathrm{p} 53$ activation by protein phosphatase $2 \mathrm{C}$ alpha. J Biol Chem 278: 14299-14305, 2003.

22. Klumpp S, Selke D and Krieglstein J: Protein phosphatase type 2C dephosphorylates BAD. Neurochem Int 42: 555-560, 2003.

23. Leroy C, Lee SE, Vaze MB, Ochsenbien F, Guerois R, Haber JE and Marsolier-Kergoat MC: PP2C phosphatases Ptc2 and Ptc3 are required for DNA checkpoint inactivation after a doublestrand break. Mol Cell 11: 827-835, 2003.

24. Kumar AS, Naruszewicz I, Wang P, Leung-Hagesteijn C and Hannigan GE: ILKAP regulates ILK signaling and inhibits anchorage-independent growth. Oncogene 23: 3454-3461, 2004.

25. Price NE and Mumby MC: Brain protein serine/threonine phosphatases. Curr Opin Neurobiol 9: 336-342, 1999.

26. Klumpp S, Selke D, Ahlemeyer B, Schaper C and Krieglstein J: Relationship between protein phosphatase type-2C activity and induction of apoptosis in cultured neuronal cells. Neurochem Int 41: 251-259, 2002.

27. Klumpp S, Selke D, Fischer D, Baumann A, Muller F and Thanos S: Protein phosphatase type-2C isozymes present in vertebrate retinae: purification, characterization, and localization in photoreceptors. J Neurosci Res 51: 328-338, 1998.

28. Jackson MD, Fjeld CC and Denu JM: Probing the function of conserved residues in the serine/threonine phosphatase PP2Calpha. Biochemistry 42: 8513-8521, 2003.

29. Kusuda K, Kobayashi T, Ikeda S, Ohnishi M, Chida N, Yanagawa Y, Shineha R, Nishihira T, Satomi S, Hiraga A and Tamura S: Mutational analysis of the domain structure of mouse protein phosphatase 2Cbeta. Biochem J 332: 243-250, 1998.

30. Holmberg CI, Tran SEF, Eriksson JE and Sistonen L: Multisite phosphorylation provides sophisticated regulation of transcription factors. Trends Biochem Sci 27: 619-627, 2002

31. Chu B, Zhong R, Soncin F, Stevenson MA and Calderwood SK: Transcriptional activity of heat shock factor 1 at $37^{\circ} \mathrm{C}$ is repressed through phosphorylation on two distinct serine residues by glycogen synthase kinase 3 and protein kinases Calpha and Czeta. J Biol Chem 273: 18640-18646, 1998.

32. Kline MP and Morimoto RI: Repression of the heat shock factor 1 transcriptional activation domain is modulated by constitutive phosphorylation. Mol Cell Biol 17: 2107-2115, 1997

33. Kim J, Nueda A, Meng YH, Dynan WS and Mivechi NF: Analysis of the phosphorylation of human heat shock transcription factor- 1 by MAP kinase family members. J Cell Biochem 67: 43-54, 1997.

34. He B, Meng YH and Mivechi NF: Glycogen synthase kinase 3 beta and extracellular signal-regulated kinase inactivate heat shock transcription factor 1 by facilitating the disappearance of transcriptionally active granules after heat shock. Mol Cell Biol 18: 6624-6633, 1998

35. Park J and Liu AY: JNK phosphorylates the HSF1 transcriptional activation domain: role of JNK in the regulation of the heat shock response. J Cell Biochem 82: 326-338, 2001. 